\title{
Neocortical Long-Term Potentiation and Long-Term Depression: Site of Expression Investigated by Infrared-Guided Laser Stimulation
}

\author{
Matthias Eder, Walter Zieglgänsberger, and Hans-Ulrich Dodt \\ Department of Clinical Neuropharmacology, Max-Planck-Institute of Psychiatry, 80804 Munich, Germany
}

The synaptic site of expression of long-term potentiation (LTP) and long-term depression (LTD) is still a matter of debate. To address the question of presynaptic versus postsynaptic expression of neocortical LTP and LTD in a direct approach, we measured the glutamate sensitivity of apical dendrites of layer 5 pyramidal neurons during LTP and LTD. We used infraredguided laser stimulation to release glutamate from its "caged" form with high spatial and temporal resolution. Responses to photolytically released glutamate and synaptically evoked EPSPs were recorded with patch-clamp pipettes from the neuronal somata. LTP and LTD could be induced by electrical stimulation at the same synapses in succession. The NMDA receptor-dependent LTD was accompanied by a decrease in the dendritic glutamate sensitivity, suggesting a postsynaptic expression of neocortical LTD. In contrast, LTP was never

Long-term potentiation (LTP) and long-term depression (LTD) of glutamatergic synapses are considered cellular correlates for learning and memory. The molecular mechanisms that underlie the induction and expression of LTP and LTD have been investigated extensively, primarily in the hippocampus. Most of the available evidence speaks in favor of a postsynaptic induction of LTP and LTD by a rise in the intracellular $\mathrm{Ca}^{2+}$ concentration. However, the synaptic site of expression of LTP and LTD is still a matter of debate.

Evidence for a postsynaptic expression of LTP and LTD is provided by several observations. (1) The amplitude of miniature EPSCs (mEPSCs) is increased (decreased) during LTP (LTD) (Manabe et al., 1992; Oliet et al., 1996). (2) Hippocampal LTP (LTD) is accompanied by a higher (lower) sensitivity of the postsynaptic membrane for exogenously applied agonists (Davies et al., 1989; Kandler et al., 1998). (3) A synaptic insertion (redistribution) of AMPA receptors occurs after the induction of LTP (LTD) (Liao et al., 1995; Lledo et al., 1998; Carroll et al., 1999; Lüscher et al., 1999; Shi et al., 1999; Hayashi et al., 2000). (4) The single-channel conductance of AMPA receptors is increased during LTP (Benke et al., 1998). (5) The late phase of LTP is accompanied by an increased synthesis of AMPA receptors (Nayak et al., 1998). (6) LTP induction is followed by an increase

\footnotetext{
Received March 25, 2002; revised May 6, 2002; accepted May 24, 2002.

This work was supported by Grant 391 from the Sonderforschungsbereich. We thank Drs. Klaus Becker and Gerhard Rammes for helpful comments on this manuscript. We also thank Drs. Thomas Gilleßen and Georg Rast for technical advice.

Correspondence should be addressed to Dr. Matthias Eder, Max-Planck-Institute of Psychiatry, Kraepelinstrasse 2, 80804 Munich, Germany. E-mail: Eder@mpipsykl. mpg.de.

Copyright (C) 2002 Society for Neuroscience $\quad 0270-6474 / 02 / 227558-11 \$ 15.00 / 0$
}

accompanied by a change in the dendritic glutamate sensitivity. A possible explanation for this finding is a presynaptic expression of neocortical LTP. Another set of experiments corroborated these results: Photolytic application of glutamate with a frequency of $5 \mathrm{~Hz}$ caused a long-lasting $\mathrm{Ca}^{2+}$ and NMDA receptor-dependent decrease in the dendritic glutamate sensitivity. In contrast, LTP of dendritic glutamate sensitivity was never induced by photostimulation, despite several experimental modifications to prevent washout of the induction mechanism and to induce a stronger postsynaptic $\mathrm{Ca}^{2+}$ influx. In conclusion, our findings provide strong evidence for a postsynaptic expression of neocortical LTD and favor a primarily presynaptic locus of neocortical LTP.

Key words: caged compounds; expression site; LTP; LTD; neocortex; photostimulation

in spine density (Trommald et al., 1996; Engert and Bonhoeffer, 1999; Weeks et al., 1999). (7) Specific subunits of the AMPA receptor are more (less) phosphorylated during LTP (LTD) (Barria et al., 1997; Lee et al., 2000).

However, there is also support for a contribution of presynaptic changes in transmitter release. It has been shown that, during LTP (LTD), the frequency of mEPSCs is increased (decreased) (Malgaroli and Tsien, 1992; Goda and Stevens, 1996). Furthermore, LTP (LTD) is accompanied by a decreased (increased) number of synaptic failures (Malinow and Tsien, 1990; Kullmann and Nicoll, 1992; Stevens and Wang, 1994; Bolshakov and Siegelbaum, 1995; Isaac et al., 1996).

Although some of these findings can also be explained by a postsynaptic activation of silent synapses (Kullmann and Siegelbaum, 1995; Malinow et al., 2000), several observations contradict this hypothesis. It has been shown that hippocampal LTP is accompanied by an enhanced transmitter release (Malgaroli et al., 1995; Zakharenko et al., 2001). Furthermore, there is evidence for an involvement of retrograde messengers (Bliss and Collingridge, 1993; Volgushev et al., 2000) and presynaptic second messengers (Arancio et al., 1995) in the expression of LTP. Thus, the question of the locus of LTP and LTD has not yet been answered.

However, in the neocortex the site of expression of LTP and LTD has not been systematically investigated, primarily because the intracortical neuronal circuitry is too complex for a rigorous quantal analysis. Thus, to elucidate the locus of neocortical LTP and LTD, we developed the method of infrared-guided laser stimulation. Because of its high temporal and spatial resolution, this technique allows one to mimic glutamatergic synaptic transmission and, simultaneously, to measure the sensitivity of the 

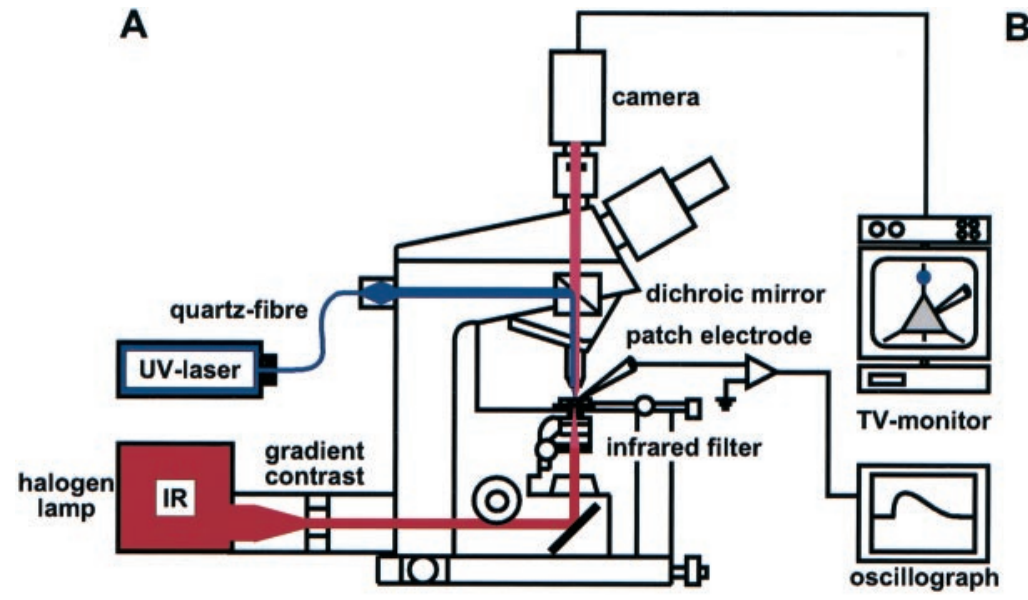

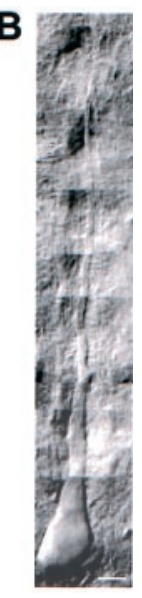

Figure 1. Infrared-guided laser stimulation. $A$, Set-up used for infrared-guided laser stimulation. Neurons in brain slices were visualized with transmitted infrared $(I R)$ light and the gradient contrast system. The beam of a UV laser was focused by the objective to a $1 \mu \mathrm{m}$ spot in the specimen plane. This way, glutamate was photolytically released from caged glutamate with high spatial and temporal resolution. The neuronal responses were recorded with patchclamp pipettes at the soma. $B$, Pyramidal neuron of neocortical layer 5 visualized by infrared videomicroscopy. Scale bar, $10 \mu \mathrm{m}$. postsynaptic membrane for photolytically applied glutamate. Part of the data presented here has been published previously as a short report (Dodt et al., 1999).

\section{MATERIALS AND METHODS}

Electrophysiology. Neocortical slices (300 $\mu \mathrm{m}$ thick, cut in a sagittal plane) were prepared, according to standard procedures (Stuart et al., 1993), from 14- to 21-d-old male Sprague Dawley rats. The animals were anesthetized with ether and then decapitated. Brain slices were placed in the recording chamber of an "infrapatch" set-up (Luigs and Neumann, Ratingen, Germany) and superfused with a solution containing (in $\mathrm{mM}$ ): $125 \mathrm{NaCl}, 2.5 \mathrm{KCl}, 1.25 \mathrm{NaH}_{2} \mathrm{PO}_{4}, 2 \mathrm{CaCl}_{2}, 1 \mathrm{MgCl}_{2}, 25 \mathrm{NaHCO}_{3}$, and 25 glucose (saturated with $95 \% \mathrm{O}_{2}$ and $5 \% \mathrm{CO}_{2}$ ), $\mathrm{pH}$ 7.4. Whole-cell recordings from visually identified somata from layer 5 pyramidal neurons of the somatosensory cortex were made at room temperature (22$24^{\circ} \mathrm{C}$ ), using a standard intracellular amplifier (npi Electronics, Tamm, Germany) operated in bridge mode. The patch-clamp electrodes with open-tip resistances of 4-7 M $\Omega$ contained (in mM): $130 \mathrm{~K}$-gluconate, 5 $\mathrm{KCl}, 0.5$ EGTA, $2 \mathrm{Mg}$-ATP, 10 HEPES, and 5 glucose, pH 7.3 (Andreasen and Hablitz, 1994). The neurons included in this study $(n=86)$ had an average resting potential of $-61 \pm 0.2 \mathrm{mV}$ and an input resistance of $98 \pm 5 \mathrm{M} \Omega$. The series resistance (on average, $14 \pm 0.2 \mathrm{M} \Omega$ ) was monitored continuously during the recordings. Perforated patch-clamp recordings $(n=10)$ were performed in voltage-clamp mode using the antibiotic amphotericin B (Sigma, Deisenhofen, Germany). Amphotericin B was dissolved in dimethylsulfoxide $(6 \mathrm{mg} / 100 \mu \mathrm{l})$ by vortex mixing and sonication. Ten microliters of this freshly prepared stock solution were dissolved in $2 \mathrm{ml}$ of pipette solution. To avoid false measurements attributable to Donnan potentials, the pipette solution contained only (in mM) $140 \mathrm{KCl}$ and $10 \mathrm{HEPES}, \mathrm{pH}$ 7.3. The patch-clamp electrodes with an open-tip resistance of $\sim 2 \mathrm{M} \Omega$ were tip-filled with an antibiotic-free pipette solution and then backfilled with the filtered $(0.22 \mu \mathrm{m}$ filter $)$ antibiotic-containing solution. The membrane of a cell-attached patch was permeabilized by amphotericin B 5-15 min after the seal formation. Additional capacitive currents appeared in response to $-10 \mathrm{mV}$ jumps of the holding potential, reflecting the capacitance of the cell. Series resistances ranged from 15 to $30 \mathrm{M} \Omega$. Electrical stimulation of synaptic input was performed with a standard bipolar tungsten stimulation electrode placed in the white matter below the recording site. The width of the electrical stimuli was $0.2 \mathrm{msec}$. In all experiments in which no synaptic stimulation was used, the presynaptic input was eliminated by the addition of tetrodotoxin (TTX, $1 \mu \mathrm{M}$; Sigma). In some experiments a potential rise in the postsynaptic $\mathrm{Ca}^{2+}$ concentration was prevented by the addition of the $\mathrm{Ca}^{2+}$ chelator 1,2-bis(2-aminophenoxy)ethane- $N, N, N^{\prime}, N^{\prime}$-tetraacetic acid (BAPTA, $10 \mathrm{~mm}$; Sigma) to the recording pipette solution. To block NMDA receptors, we used (+)-5-methyl-10,11-dihydro-5H-dibenzo [a,d] cyclohepten-5,10-imine maleate (M K801) (20 $\mu \mathrm{M}$; Tocris, Köln, Germany). All data were stored and analyzed using a Macintosh-based recording system (Pulse 8.00; Heka Elektronik, Lambrecht/Pfalz, Germany) and standard software (Igor Pro 3.01; WaveMetrics Inc., Lake Oswego, OR). All values were expressed as means \pm SEM. Statistical evaluation was performed using the Student's $t$ test.

Photostimulation. Neurons in neocortical slices were visualized with infrared light and a new contrast system, "gradient contrast" (Dodt et al.,
1999) (Fig. 1A,B). The power of an ultraviolet (UV) laser (Enterprise II; Coherent, Dieburg, Germany) was adjusted with its remote control to evoke a depolarizing glutamate or hyperpolarizing GABA response of $\sim 3-5 \mathrm{mV}$ at the soma. The duration of the shuttered light pulses (Uniblitz shutter; Vincent Associates, Rochester, NY) was 3 msec. The beam of the argon ion laser was focused by the objective $(60 \times, 0.9$ numerical aperture; Olympus, Hamburg, Germany) to a $1 \mu \mathrm{m}$ spot in the specimen plane (Fig. 1A). Glutamate or GABA was applied by the photolysis (wavelength, 351-364 nm) of $\gamma$-CNB [( $\alpha$-carboxy-2nitrobenzyl)-caged glutamate] $(0.25-0.5 \mathrm{~mm})$ or $\gamma$-CNB-caged GABA (1 mM) (Molecular Probes, Leiden, The Netherlands) added to the superfusion solution, which was oxygenated in a recirculation system. Pure $\mathrm{GABA}_{\mathrm{A}}$ receptor-mediated responses were isolated by the addition of the specific $\mathrm{GABA}_{\mathrm{B}}$ receptor antagonist $p$-(3-aminopropyl)- $p$ diethoxymethyl-phosphinic acid (CGP35348) (200 $\mu \mathrm{M}$; gift from CibaGeigy). Caged glutamate reaches its maximal effect 10 min after the beginning of the superfusion (Dodt et al., 1998), and caged GABA reaches its maximal effect $20 \mathrm{~min}$ after the beginning of the superfusion (Eder et al., 2001). Therefore, the photostimulation experiments using caged glutamate were started at least 15 min after addition of the caged compound; those using caged GABA were started at least 30 min after addition of the caged compound.

\section{RESULTS}

Responses to glutamate, delivered photolytically to one site of the apical dendrite, as well as electrically evoked EPSPs were recorded from the somata of layer 5 pyramidal neurons at the resting potential. After a stable whole-cell patch-clamp recording had been established, the recording chamber was perfused with a solution containing caged glutamate $(0.25-0.5 \mathrm{mM})$. In all experiments without synaptic stimulation, TTX $(1 \mu \mathrm{M})$ was added to isolate the neuron under study from synaptic inputs. The caged compound was photolyzed by $3 \mathrm{msec}$ light pulses of a UV laser (Fig. 1A).

\section{Characterization of infrared-guided laser stimulation Caged glutamate}

To test whether spontaneously hydrolyzed caged glutamate desensitizes glutamate receptors, we compared the rise time $(20-$ $80 \%$ ) and amplitude of evoked EPSPs before and after the addition of caged glutamate to the superfusion medium. Neither the rise time nor the amplitude changed significantly (Fig. 2A,B). The rise time was $5.0 \pm 0.7 \mathrm{msec}$ in the absence and $4.5 \pm 0.6$ msec in the presence of caged glutamate $(p>0.1)$. The values for the amplitude were $6.3 \pm 0.8 \mathrm{mV}$ before the addition and $6.1 \pm$ $0.9 \mathrm{mV}$ after the addition of the caged compound $(p>0.5)$. The respective values of 15 EPSPs in the absence and presence of caged glutamate were averaged for six neurons. Furthermore, no change in the resting membrane potential of the recorded neuron 
A
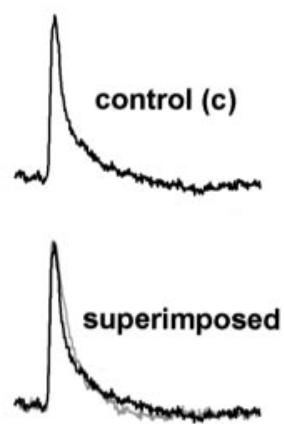

B

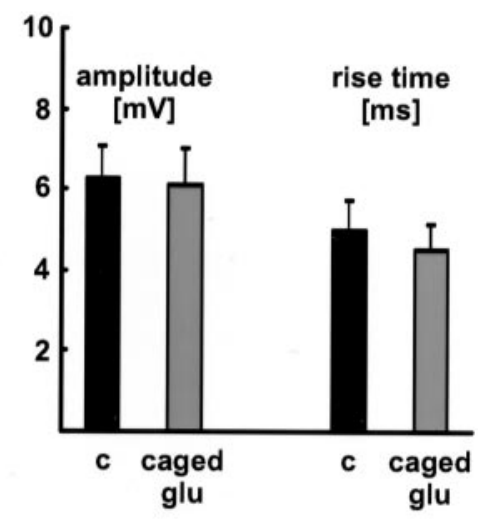

Figure 2. Characterization of infrared-guided laser stimulation. $A, B$, Caged glutamate does not desensitize glutamate receptors by spontaneous hydrolyzation. Neither the rise time nor the amplitude of evoked EPSPs changed significantly when caged glutamate (caged glu) was added to the extracellular medium. In $A$, single sweeps are shown. $B$, Statistical evaluation. The respective values of 15 EPSPs under control conditions $(c)$ and in the presence of caged glutamate were averaged for six neurons. $C, D$, Spatial specificity of infrared-guided laser stimulation. The laser point was moved laterally away from the dendrite in increments of $2.5 \mu \mathrm{m}$. The decrease in glutamate response amplitude is plotted as a function of this distance. In $C$, a single experiment is shown. $D$, Only the data of one side were pooled $(n=6$ neurons), because the typical Gaussian shape of the other side was sometimes distorted. This may be an effect of invisible dendritic branches.
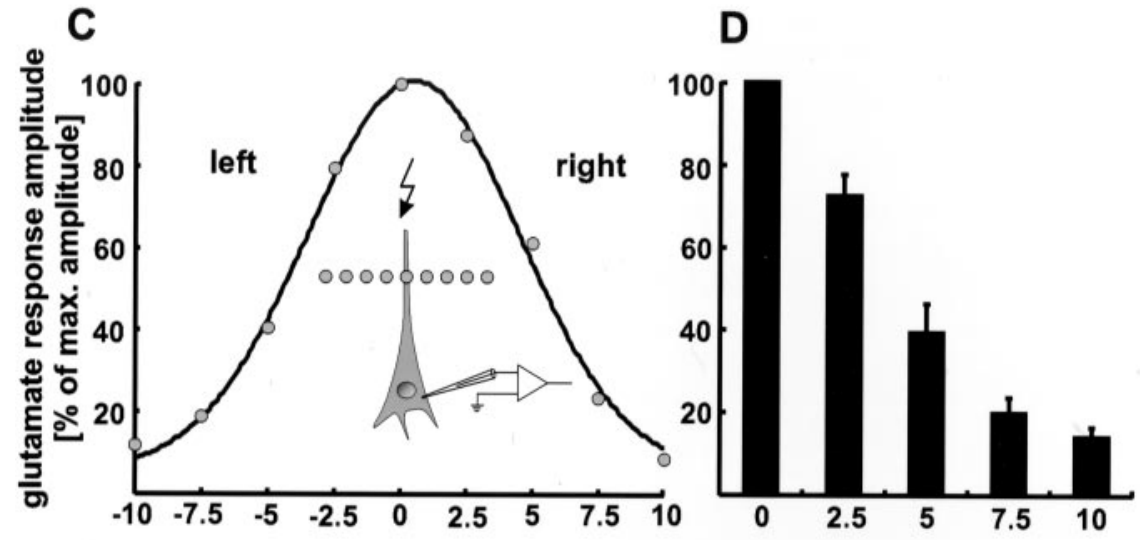

lateral distance from dendrite $[\mu \mathrm{m}]$ or in the spontaneous synaptic activity of the brain slice was observed. These results show that caged glutamate does not desensitize glutamate receptors by spontaneous hydrolyzation.

\section{Spatial specificity}

High spatial resolution is one of the advantages of infraredguided laser stimulation. To quantify the spatial specificity, the laser point was moved laterally away from the dendrite in increments of $2.5 \mu \mathrm{m}$. As a result, the amplitude of the depolarizing glutamate response decreased with distance. The full width half maximum (FWHM) in the lateral direction obtained this way was $4.1 \pm 1 \mu \mathrm{m}$ ( $n=6$ neurons) (Fig. $2 C, D)$. The FWHM in the axial direction was $18 \pm 2 \mu \mathrm{m}$ ( $n=4$ neurons). Thus, the site of glutamate release can be estimated as a spot with a diameter of $10 \mu \mathrm{m}$.

\section{Photostimulation LTD}

\section{Induction}

To resolve the expression site(s) of neocortical LTP and LTD, we tried to induce LTP- or LTD-like phenomena by photostimulation. For this, the UV spot was positioned on the dendrite at distances of 100-150 $\mu \mathrm{m}$ from the soma. This was done for the following reasons: (1) In this region (layer 4), many thalamocortical afferents form glutamatergic synapses with the apical dendrite of layer 5 pyramidal neurons (Peters, 1987). (2) Thalamocortical synapses express LTP as well as LTD (Feldman et al., 1998). Because presynaptic input was blocked by TTX, changes in the dendritic responsiveness to glutamate had to be of postsynaptic origin.
Before and after a tetanus-like stimulation, glutamate was released with a frequency of $0.05 \mathrm{~Hz}$. A train of $5-20 \mathrm{~Hz}$ light flashes always elicited a decrease in glutamate response amplitude [photostimulation-LTD (photo-LTD)] but never an increase in dendritic glutamate sensitivity. Therefore, the results regarding LTD are described below first.

A train of $5 \mathrm{~Hz}$ light flashes for a 1 min duration was used as the standard stimulation paradigm. Photo-LTD appeared immediately after the $5 \mathrm{~Hz}$ light tetanus and lasted for the entire time of recording $(1 \mathrm{hr})$ (Fig. $3 A)$. The significant decrease $(p<0.01)$ in the glutamate response amplitude was $33 \pm 2 \%$ ( $n=9$ neurons; data from 16 to $20 \mathrm{~min}$ after the $5 \mathrm{~Hz}$ train are pooled). Interestingly, an additional depolarization of the neuron by current injection (Kandler et al., 1998) was not necessary to induce photo-LTD. This may be attributable to the summation of the depolarizing glutamate responses evoked by the $5 \mathrm{~Hz}$ train. Depolarization of the neuron to approximately $-50 \mathrm{mV}$ was caused by $5 \mathrm{~Hz}$ uncaging. This was also the case for the experiments described below.

To exclude the possibility that photo-LTD is caused by damage to the neuron attributable to UV radiation, control experiments were performed. After establishing a baseline, caged glutamate was washed out of the slice, the $5 \mathrm{~Hz}$ train was applied, and then caged glutamate was washed in again. During the following period of control stimulation, no significant reduction in glutamate response amplitude was observed $(+3 \pm 4 \% ; p>0.5 ; n=$ 3 neurons). In contrast, an additional application of the $5 \mathrm{~Hz}$ train, now in the presence of caged glutamate, induced a robust 


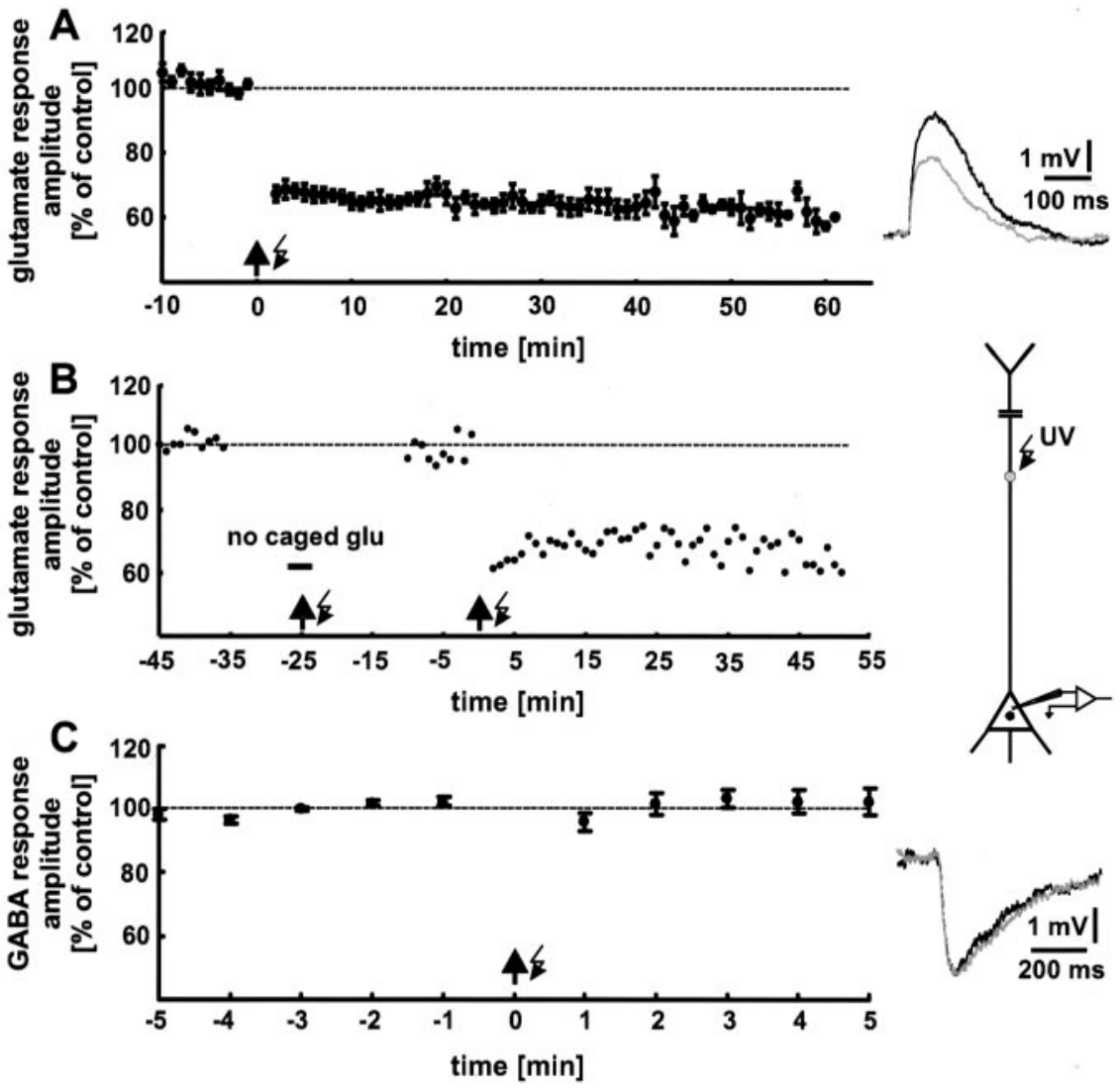

Figure 3. Tetanic release of glutamate causes a decrease in the glutamate response amplitude (photoLTD). $A$, Focal photolysis of caged glutamate with a frequency of $5 \mathrm{~Hz}$ for $1 \mathrm{~min}$ duration (arrow with flash symbol) reliably elicited photo-LTD. For control stimulation, glutamate was released every $20 \mathrm{sec}$. The data shown are averages for every minute. The $100 \%$ value (dashed line) represents the mean of the last $5 \mathrm{~min}$ before the onset of the $5 \mathrm{~Hz}$ train in all figures. The traces show single glutamate responses before (black) and after (gray) $5 \mathrm{~Hz}$ stimulation. $B$, Photo-LTD is not caused by damage to the neuron attributable to the UV radiation. The glutamate responses were not affected by the $5 \mathrm{~Hz}$ train when applied in the absence of caged glutamate. In contrast, a second application of the $5 \mathrm{~Hz}$ stimulation in the presence of caged glutamate reliably induces photo-LTD. A single experiment is shown. $C$, Photo-LTD is not induced by the photolytically released caging group. The amplitudes of GABA responses, elicited by photolysis of caged GABA, were not affected by the $5 \mathrm{~Hz}$ stimulation. Because the caged glutamate and caged GABA used are protected by the same caging group, photoLTD cannot be caused by the photolytically released caging group. The traces show single GABA responses before (black), and after (gray) the $5 \mathrm{~Hz}$ stimulation.
photo-LTD (Fig. 3B). Thus, our photo-LTD was not caused by damage to the neurons attributable to UV radiation. Furthermore, this result demonstrates that photo-LTD can be induced after a recording time of $45 \mathrm{~min}$, and thus the induction mechanism is not washed out.

Additional control experiments showed that photo-LTD was also not induced by the photolytically released caging group. As shown in Figure $3 C$, a reduction in the response amplitude could not be elicited when GABA was released from caged GABA by the $5 \mathrm{~Hz}$ train ( $n=6$ neurons). Pure $\mathrm{GABA}_{\mathrm{A}}$ receptor-mediated responses were isolated by addition of the specific $\mathrm{GABA}_{\mathrm{B}}$ receptor antagonist CGP35348 (200 $\mu \mathrm{M})$ (Eder et al., 2001). Because the caged glutamate used, as well as the caged GABA, is protected by the same caging group $(\mathrm{CNB})$, the induction of photo-LTD by the photolytically released caging group can be excluded.

\section{$\mathrm{Ca}^{2+}$ and $\mathrm{NMDA}$ receptor dependence}

Hippocampal as well as neocortical LTP and LTD are induced by a rise in the postsynaptic $\mathrm{Ca}^{2+}$ concentration, which is primarily mediated by NMDA receptors (Malenka, 1995). To examine whether photo-LTD is also $\mathrm{Ca}^{2+}$ and NMDA receptor dependent, we performed two sets of experiments. (1) A rise in the postsynaptic $\mathrm{Ca}^{2+}$ concentration was prevented by addition of the $\mathrm{Ca}^{2+}$ chelator BAPTA $(10 \mathrm{~mm})$ to the recording pipette solution. Under these conditions, only a slight reduction in glutamate response amplitude was observed $(9 \pm 3 \% ; n=8$ neurons; data from 16 to $20 \mathrm{~min}$ after the $5 \mathrm{~Hz}$ train are pooled) (Fig. $4 A$ ). Compared with the slight decrease in glutamate response amplitude, which was observed in control experiments in which neither the $5 \mathrm{~Hz}$ stimulation nor BAPTA was applied (Fig. $5 A$, white squares), the reduction in the presence of BAPTA was not sig- nificant $(p>0.05)$. (2) Addition of the NMDA receptor blocker MK801 $(20 \mu \mathrm{M})$ to the extracellular solution also blocked photoLTD $(7 \pm 2 \% ; p>0.05 ; n=8$ neurons) (Fig. $4 B)$, in combination with an increase in the extracellular $\mathrm{Mg}^{2+}$ concentration from 1 to $4 \mathrm{~mm}$. These results show that photo-LTD is $\mathrm{Ca}^{2+}$ and NMDA receptor dependent and thus shares common features with synaptic LTD.

The block of NMDA receptors caused a reduction in glutamate response amplitude of $39 \pm 3 \%(n=6$ neurons with a mean resting potential of $-62 \pm 1 \mathrm{mV})$. For each neuron the amplitudes of 15 glutamate responses were averaged (Fig. $4 C$ ).

\section{Photostimulation LTP}

In many brain structures, including the neocortex and the hippocampus, glutamatergic synapses are susceptible to both LTP and LTD. It has been shown for neocortical pyramidal cells that the polarity of the synaptic gain change depends on the amplitude of the postsynaptic rise in the $\mathrm{Ca}^{2+}$ concentration. The threshold for the induction of LTD is lower than for the induction of LTP (Hansel et al., 1997). To test whether an increase in glutamate response amplitude (photo-LTP) can also be induced by photostimulation, we performed experiments with the following modifications. (1) The extracellular $\mathrm{Ca}^{2+}$ concentration was increased from 2 to $4 \mathrm{~mm}$. (2) The neuron under study was depolarized to $-30 \mathrm{mV}$ during the $5 \mathrm{~Hz}$ train. (3) The frequency of the induction protocol was increased to $10-20 \mathrm{~Hz}$. (4) These modifications were combined. Interestingly, expression of photoLTP was never observed. Possible explanations for this finding are that, despite the experimental modifications, the intracellular $\mathrm{Ca}^{2+}$ concentration did not reach the threshold for LTP induction or that neocortical LTP is expressed presynaptically. 
Figure 4. Photo-LTD is $\mathrm{Ca}^{2+}$ and NMDA receptor dependent. $A$, Addition of the $\mathrm{Ca}^{2+}$ chelator BAPTA to the pipette solution blocks photo-LTD. Only an insignificant reduction in glutamate response amplitude remains. $B$, The block of NMDA receptors by MK801 and a high external $\mathrm{Mg}^{2+}$ concentration prevents the induction of photo-LTD. The reduction in glutamate response amplitude is statistically insignificant. Dashed lines represent the $100 \%$ value. C, Approximately $40 \%$ of the amplitude of the photolytically evoked glutamate response is mediated by NMDA receptors at resting membrane potential. The traces show single glutamate responses before (black) and after ( gray) blockade of the NMDA receptors. The faster kinetics of the AMPA receptor-mediated component is clearly recognizable if the sweeps are scaled.
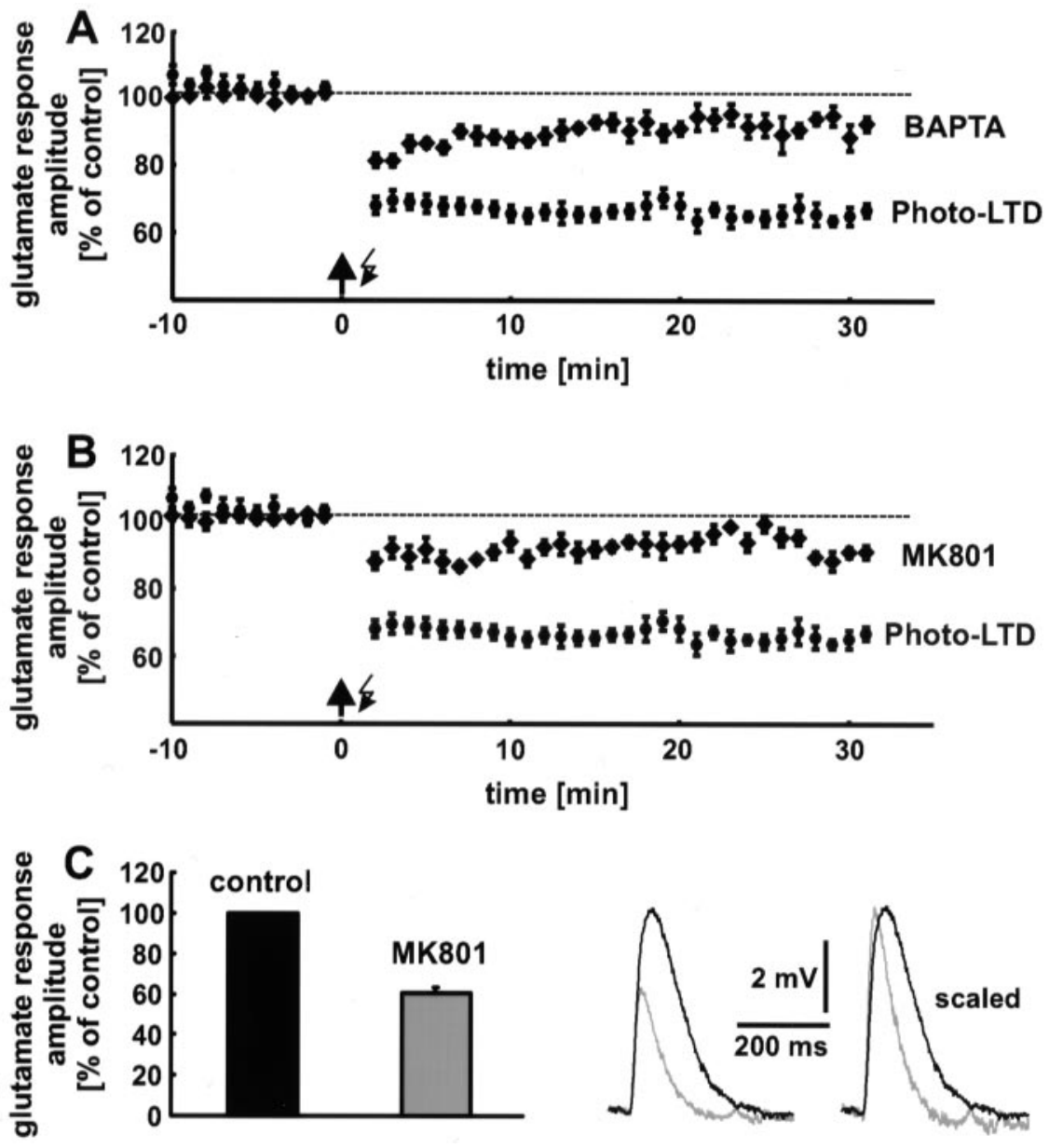

\section{Synaptic LTD}

\section{Induction}

Photo-LTD results from a reduction in postsynaptic glutamate sensitivity. To test whether synaptic LTD is also expressed by a decrease in dendritic glutamate sensitivity, we combined the techniques of photostimulation and synaptic stimulation. Electrical stimulation of synaptic input was performed by a tungsten electrode, positioned in the white matter below the recorded neuron. To simultaneously measure the glutamate sensitivity of the postsynaptic dendritic membrane, glutamate was photolytically released. During the control and follow-up periods, electrical stimulation and photostimulation were performed every 20 sec, with an interval of $10 \mathrm{sec}$ between the two kinds of stimulation. To activate a large number of synapses during the $5 \mathrm{~Hz}$ train, we used a higher electrical stimulation intensity $(2 \times$ the threshold of spike generation) (Staubli and Lynch, 1990) than that used to elicit control EPSPs. In most neurons, this kind of $5 \mathrm{~Hz}$ stimulation induced synaptic LTD. The reduction in EPSP amplitude was $32 \pm 6 \%$ on average ( $n=14$ neurons; $p<0.01$; data from 46 to 50 min after the electrical LTD induction are pooled) (Fig. $5 A$, white circles). As with photo-LTD, synaptic LTD appeared immediately after the $5 \mathrm{~Hz}$ train and lasted for the entire time of the recording (1 hr).

\section{Decrease in dendritic glutamate sensitivity during synaptic LTD}

Figure $5 A$ (black diamonds) shows that the dendritic glutamate sensitivity decreases significantly during synaptic LTD. Forty-eight minutes after the $5 \mathrm{~Hz}$ train, the glutamate sensitivity reached the same amount of amplitude reduction ( $31 \pm 3 \% ; n=8$ neurons; $p<$ 0.01 ; data from 46 to $50 \mathrm{~min}$ after electrical LTD induction are averaged) (Fig. 5C, black bar) as synaptic LTD (white bar) and photo-LTD $(33 \pm 2 \%)$ (Fig. $3 A)$. Without LTD induction, the glutamate response was stable for the entire time of recording (60 min) (Fig. $5 A$, white squares). Only a minor rundown of the glutamate response amplitude was observed $(2 \pm 4 \% ; p>0.2 ; n=5$ neurons; data from 46 to $50 \mathrm{~min}$ are pooled).

Interestingly, the time courses of synaptic LTD and reduction in glutamate sensitivity are different (Fig. 5A). The decrease in glutamate sensitivity developed more slowly than synaptic LTD. Nevertheless, $35 \mathrm{~min}$ after LTD induction this difference was insignificant $(p>0.5)$. Thus, the reduction in postsynaptic glutamate sensitivity is sufficient to explain synaptic LTD after 30 min, the time point usually taken as the beginning of LTD.

\section{Occlusion of photostimulation LTD by synaptic LTD}

Additional evidence for a common postsynaptic expression mechanism of photo-LTD and synaptic LTD was provided by occlusion experiments. Forty minutes after triggering synaptic LTD, the $5 \mathrm{~Hz}$ train of light flashes for photo-LTD induction was applied to 6 of the 14 neurons pooled in Figure $5 A$. At this point, no additional photo-LTD could be elicited in these neurons $(p>$ 0.1 ) (Fig. 5A, gray diamonds). In other words, synaptic LTD completely occludes photo-LTD. Forty-eight minutes after the electrical $5 \mathrm{~Hz}$ stimulation, the reduction in glutamate response 

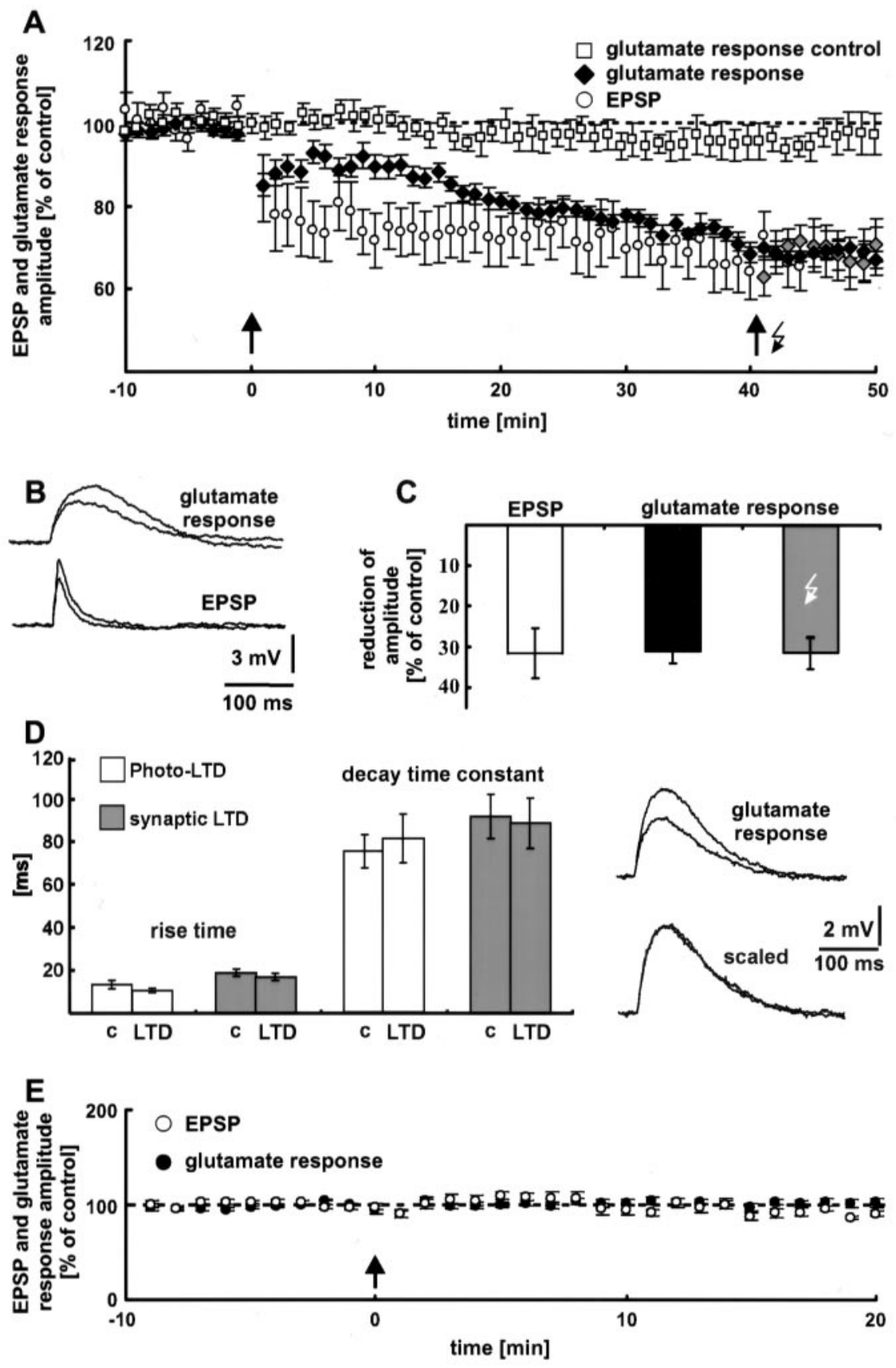

Figure 5. Neocortical synaptic LTD. A, Electrical 5 $\mathrm{Hz}$ stimulation (arrow) induces LTD of EPSPs. This form of synaptic plasticity is associated with a decrease in the dendritic glutamate sensitivity. To 6 of the 14 neurons, the $5 \mathrm{~Hz}$ train of light flashes (arrow with flash symbol) was applied. No additional photoLTD could be elicited in these neurons ( gray diamonds), indicating a complete occlusion of photoLTD by synaptic LTD. Without LTD induction, the glutamate response was stable for the entire time of recording (60 min, white squares). The dashed line represents the $100 \%$ value. $B$, Traces of glutamate responses and EPSPs before and 35 min after electrical $5 \mathrm{~Hz}$ stimulation. Depolarizations elicited by photostimulation had a time-to-peak $(62 \pm 3 \mathrm{msec})$ that was approximately three times as long as the time-topeak of electrically evoked EPSPs $(20 \pm 2 \mathrm{msec} ; n=$ 7 neurons). $C$, Comparison of the reduction in EPSP amplitude (white bar) and glutamate response peak (black bar) during synaptic LTD. Forty-eight minutes after electrical LTD induction, both potentials show no difference $(p>0.5)$. The gray bar indicates the mean reduction in the glutamate response amplitude of the neurons, which were also stimulated by a $5 \mathrm{~Hz}$ light tetanus. $D$, Photo-LTD and synaptic LTD are not associated with a change in the glutamate response kinetics. Traces show single glutamate responses before and after the $5 \mathrm{~Hz}$ stimulation. The unchanged kinetics of the glutamate responses is clearly recognizable if the sweeps are scaled. $c$, Control. E, Synaptic LTD is NMDA receptor dependent. Blockade of NMDA receptors by MK801 and a high extracellular $\mathrm{Mg}^{2+}$ concentration prevented the induction of synaptic LTD and the decrease in dendritic glutamate sensitivity ( $n=7$ neurons). The arrow indicates electrical $5 \mathrm{~Hz}$ stimulation (see $A$ ). The dashed line represents the $100 \%$ value. amplitude was $31 \pm 2 \%$ (data from 46 to 50 min after electrical LTD induction are averaged) (Fig. $5 C$, gray bar).

\section{Kinetics of the glutamate response during} photostimulation LTD and synaptic LTD

As shown in Figure 5D, photo-LTD and synaptic LTD were not associated with a change in the glutamate response kinetics. The average rise time $(20-80 \%)$ was $13 \pm 2 \mathrm{msec}$ before and $11 \pm 1$ msec during photo-LTD ( $p>0.05 ; n=6$ neurons; data from the last $5 \mathrm{~min}$ of the control stimulation and 21-25 min after the $5 \mathrm{~Hz}$ train are pooled). The respective values for synaptic LTD are $19 \pm 2$ and $17 \pm 2 \operatorname{msec}(p>0.1 ; n=8$ neurons; data from the last $5 \mathrm{~min}$ of the control stimulation and 26-30 min after the $5 \mathrm{~Hz}$ train are averaged). Control values of the decay time constant were determined as $75 \pm 8 \mathrm{msec}$ for photo-LTD and $91 \pm 10$ msec for synaptic LTD. After the $5 \mathrm{~Hz}$ train, the decay time constant was $81 \pm 11 \mathrm{msec}(p>0.1)$ and $88 \pm 12 \mathrm{msec}(p>0.5)$, respectively. In addition, this result suggests equal expression mechanisms of photo-LTD and synaptic LTD.

\section{NMDA receptor dependence of synaptic LTD}

NMDA receptors, voltage-dependent $\mathrm{Ca}^{2+}$ channels, and metabotropic glutamate receptors mediate the postsynaptic rise in the $\mathrm{Ca}^{2+}$ concentration, which is essential for the induction of neocortical LTD (Malenka, 1995). To test whether the observed synaptic LTD is also NMDA receptor dependent, as is photoLTD, the NMDA receptor blocker MK801 (20 $\mu \mathrm{M})$ was added to the extracellular medium, and the external $\mathrm{Mg}^{2+}$ concentration was increased from 1 to $4 \mathrm{~mm}$. Under these conditions, the same as those used to block photo-LTD, synaptic LTD was never elicited by the electrical $5 \mathrm{~Hz}$ stimulation. Furthermore, the dendritic glutamate sensitivity remained constant (Fig. 5E). Only 
an insignificant reduction in EPSP amplitude $(8 \pm 3 \% ; p>0.05)$ and glutamate response peak $(0 \pm 4 \% ; p>0.5 ; n=7$ neurons; data from 16 to $20 \mathrm{~min}$ after the $5 \mathrm{~Hz}$ train are pooled) was observed. The fact that photo-LTD is NMDA receptor dependent, as is synaptic LTD, provides evidence for equal induction mechanisms of these forms of long-term plasticity.

\section{Synaptic LTP}

\section{Induction}

In most neurons under study, electrical $5 \mathrm{~Hz}$ stimulation induced synaptic LTD. Nevertheless, in 5 of 19 neurons, the $5 \mathrm{~Hz}$ train was followed by LTP. This finding suggests that the intracellular $\mathrm{Ca}^{2+}$ concentration reached a value near the modification threshold $\theta_{\mathrm{m}}$. At $\theta_{\mathrm{m}}$, according to the sliding threshold hypothesis (Bear, 1995), LTD reverses to LTP and vice versa. To induce a stronger rise of the intracellular $\mathrm{Ca}^{2+}$ concentration and therefore a more reliable LTP, the stimulation intensity was increased from $2 \times$ to $2.5 \times$ the threshold of spike generation.

Figure $6 A$ shows the pooled data of 12 neurons that expressed LTP (white circles). These LTP-expressing cells were selected from a larger sample of 29 neurons: Using a stimulation intensity of $2 \times$ the threshold of spike generation (7.2-12.2 V), five cells expressed LTP and 14 neurons expressed LTD. Using a stimulation intensity of $2.5 \times$ the threshold of spike generation (10.0-14.8 V), seven cells showed LTP, two neurons showed LTD, and one cell showed no synaptic plasticity. Regarding LTP, the average increase in the EPSP amplitude was $48 \pm 11 \%$ (Fig. $6 C$, first bar) ( $p<0.01$; data from 16 to 20 min after electrical LTP induction are averaged). Like photo-LTD and synaptic LTD, synaptic LTP appeared immediately after the $5 \mathrm{~Hz}$ train.

\section{Dendritic glutamate sensitivity during synaptic LTP}

Corresponding to the decrease in glutamate response amplitude during synaptic LTD, a postsynaptic expression of neocortical LTP should lead to an increase in dendritic glutamate sensitivity. However, in our experiments the glutamate response amplitude remained constant during synaptic LTP (Fig. 6, black diamonds in $A$, second bar in $C)(-3 \pm 2 \% ; p=0.1$; data from 16 to $20 \mathrm{~min}$ after electrical LTP induction are averaged).

One could argue that the dendritic location of the synapses expressing LTP did not correspond to the region in which glutamate was released by photolysis. In this case, a change in glutamate sensitivity would not have been detected. To exclude this possibility, we performed experiments in which LTP and LTD were induced at the same synapses in succession. Figure $6 B$ shows the pooled data from these experiments ( $n=7$ neurons). Synaptic LTP was not accompanied by a reduction in dendritic glutamate sensitivity. In contrast, during synaptic LTD the glutamate response amplitude decreased significantly $(17 \pm 5 \% ; p<0.01$; data from 36 to $40 \mathrm{~min}$ after electrical LTD induction are averaged) (Fig. 6C, fourth bar). The average reduction in EPSP amplitude was $26 \pm 5 \%(p<0.01)$ (Fig. 6C, third bar).

\section{Perforated patch-clamp recordings}

A possible explanation for the absence of photo-LTP and the unchanged dendritic glutamate sensitivity during synaptic LTP is a presynaptic expression of neocortical LTP. Alternatively, these findings could be almost entirely explained on the basis of washout of the induction mechanism. Furthermore, LTD might be more resistant to washout than LTP. This could explain why we were unable to induce photo-LTP. But why were we able to induce LTP synaptically? A possible explanation is that synapses on distal dendrites are more resistant to washout, and this was the locus of LTP. However, the laser uncaging was performed relatively proximally on the visible apical dendrite. In addition, uncaging appeared to induce a significant NMDA component (Fig. $4 C$ ). It is possible that this inevitably recruited the LTD cascade right from the start of photostimulation.

We tested these hypotheses experimentally: To prevent washout of the induction mechanism, the cells were recorded using the perforated patch-clamp technique. Before and after the induction, neurons were held at $-80 \mathrm{mV}$. At this potential, the glutamate response is mediated primarily by AMPA receptors. To maximize $\mathrm{Ca}^{2+}$ influx during the induction, the extracellular $\mathrm{Ca}^{2+}$ concentration was increased from 2 to $4 \mathrm{~mm}$ and the cells were depolarized to $0 \mathrm{mV}$. During depolarization, glutamate was released photolytically five times with a frequency of $50 \mathrm{~Hz}$ for 2 sec (pairing procedure). The interstimulus interval was $10 \mathrm{sec}$. This protocol reliably induces synaptic LTP on layer 5 pyramidal neurons of the neocortex of young rats (Tsumoto, 1992). However, we observed a strong photo-LTD in all experiments (53 \pm $6 \% ; p<0.001 ; n=5$ neurons; data from 16 to 20 min after the pairing procedure are pooled) (Fig. 7, black circles). This was also the case if glutamate was released by the standard $5 \mathrm{~Hz}$ train (1 min) at the normal extracellular $\mathrm{Ca}^{2+}$ concentration of $2 \mathrm{~mm}$ (48 $\pm 7 \% ; p<0.01 ; n=5$ neurons) (Fig. 7 , white squares). These results make it highly unlikely that the absence of photo-LTP and the unchanged dendritic glutamate sensitivity during synaptic LTP are caused by a washout of the induction mechanism.

\section{DISCUSSION}

Our experiments provide strong evidence for a postsynaptic expression of neocortical LTD and, although more indirect, they favor a presynaptic expression of neocortical LTP. What is the evidence for a presynaptic locus of LTP? Like Kandler et al. (1998), we never observed a photostimulation-induced increase in glutamate response amplitude (photo-LTP), despite several experimental modifications to induce a stronger postsynaptic $\mathrm{Ca}^{2+}$ influx. Furthermore, uncaging of glutamate in combination with perforated patch-clamp recording also produced only photoLTD, independent of the different induction protocols used. Thus, it is highly unlikely that the impossibility of inducing photo-LTP and the unchanged dendritic glutamate sensitivity during synaptic LTP are the result of washout of the induction mechanism. One possible explanation for why photo-LTP was never observed is that neocortical LTP is expressed primarily presynaptically. A presynaptic change would not be detected by measuring the postsynaptic glutamate sensitivity. Our experiments support this hypothesis: LTP, induced by electrical stimulation, is not accompanied by a change in glutamate response amplitude, in contrast to the decrease in glutamate sensitivity during LTD. This is also found when LTP and LTD are induced at the same synapses in succession. All of these conclusions depend on the assumption that photolytically released glutamate has access to receptors that are activated synaptically. Recently, this has been directly shown by Matsuzaki et al. (2001).

The method of infrared-guided laser stimulation allows one to mimic synaptic transmission. Nevertheless, responses to photolytically released glutamate show a somewhat longer time course than synaptically evoked potentials/currents. Furthermore, the photolytic glutamate transient is less focused than the synaptic glutamate transient. One could argue that because of this spatiotemporal difference, the photolytically triggered rise in the postsynaptic $\mathrm{Ca}^{2+}$ concentration is not sufficient to activate kinases, and thus, photo-LTP cannot be induced. We cannot rule 


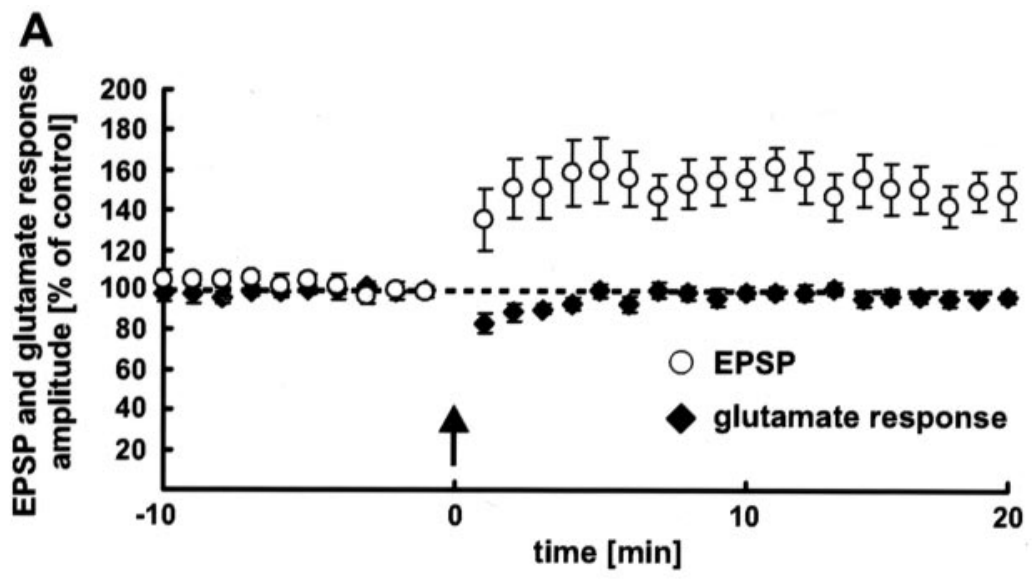

B
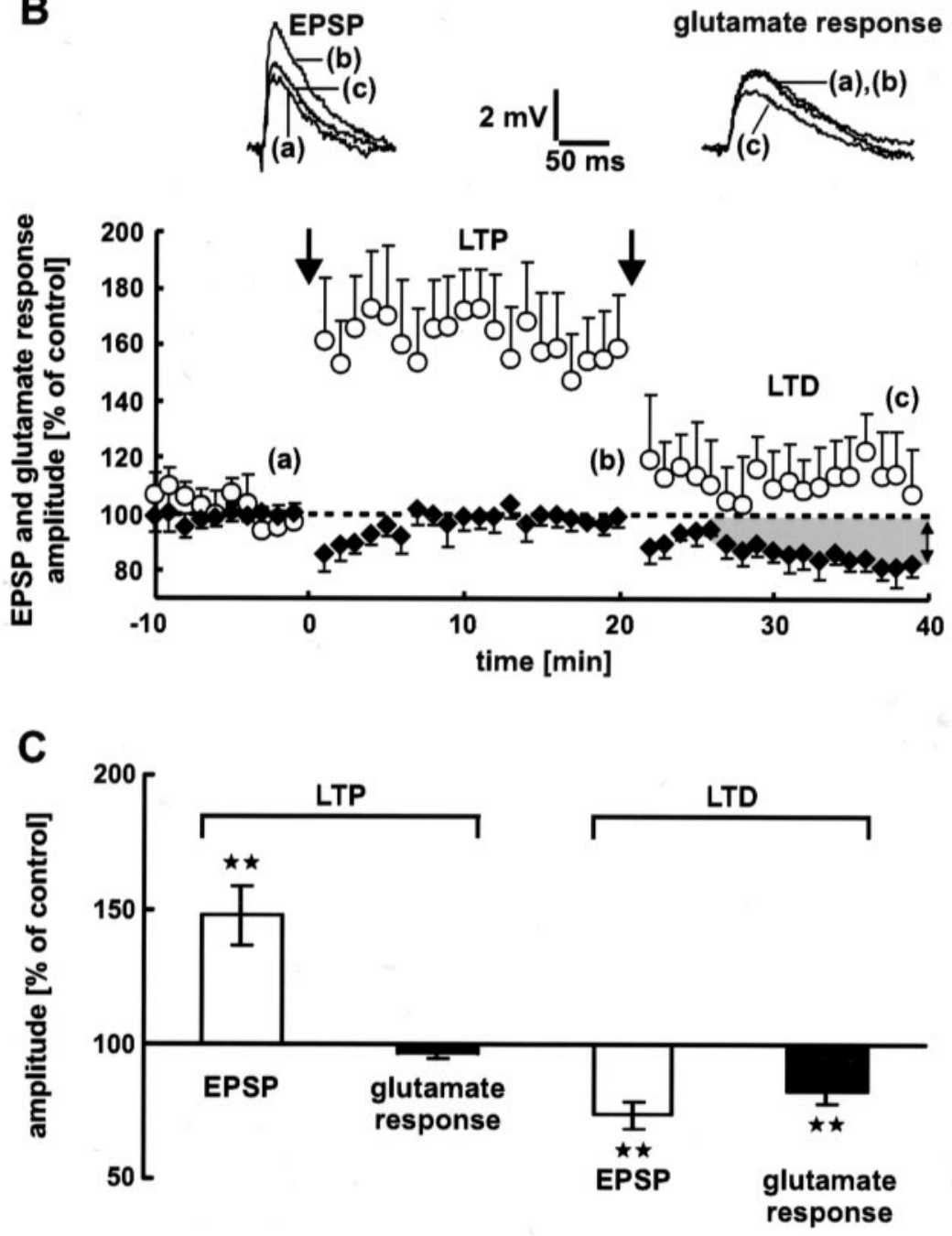

Figure 6. Neocortical synaptic LTP. A, Electrical stimulation (arrow) induces LTP of EPSPs. During LTP, the dendritic glutamate sensitivity does not change. Averages of 12 neurons are shown. $B$, Dendritic glutamate sensitivity during synaptic LTP and LTD successively induced at the same synapses. LTP and LTD were induced by electrical $5 \mathrm{~Hz}$ stimulation ( $n=7$ neurons). The stimulation intensities used for LTP and LTD induction were $2.5 \times$ and $2 \times$ the threshold of spike generation, respectively. The dendritic glutamate sensitivity during LTP remains constant. In contrast, LTD is associated with a decrease in the glutamate response amplitude. The traces show single EPSPs and glutamate responses. Dashed lines represent the $100 \%$ value. $C$, Statistical evaluation of the experiments shown in $A$ and $B$. A high significant difference $(p<0.01)$ from the control value is indicated by the stars. As a control value for LTD, the mean of the last 5 min (16-20 $\mathrm{min}$ ) before LTD induction was used. During synaptic LTP, the glutamate response amplitude shows no significant difference $(p=0.1)$. out this possibility completely. However, the following argues against it. Typical stimulation frequencies for the induction of synaptic LTP are 50-100 Hz. Such a high-frequency stimulation induces a continuous depolarization of the neuron during the tetanus, causing a strong tonic activation of NMDA receptors and thus a continuous rise in the postsynaptic $\mathrm{Ca}^{2+}$ concentration. This is facilitated by the high affinity of NMDA receptors to glutamate and their slow kinetics. Therefore, it does not seem to be essential to mimic a single synaptic response exactly by laser uncaging if a high-frequency induction protocol is used. However, $50 \mathrm{~Hz}$ photostimulation in combination with a high extracellular $\mathrm{Ca}^{2+}$ concentration and depolarization of the neuron to $0 \mathrm{mV}$ never produced photo-LTP but reliably produced photo-LTD in our experiments.

Synaptically released glutamate binds primarily to receptors of the postsynaptic density. In contrast, photolytically released glu- 
Figure 7. Perforated patch-clamp recordings. To prevent a potential washout of the induction mechanism of LTP, the cells were recorded using perforated patch-clamp techniques. Photolytic release of glutamate induced photo-LTD in all neurons independently of the induction protocol used. The dashed line represents the $100 \%$ value.
$50 \mathrm{~Hz} ; 2 \mathrm{~s}, 5$ trains $/ 4 \mathrm{mM}\left[\mathrm{Ca}^{2+}\right.$ 。

$5 \mathrm{~Hz} ; 1 \mathrm{~min} / 2 \mathrm{mM}\left[\mathrm{Ca}^{2+}\right]_{0}$

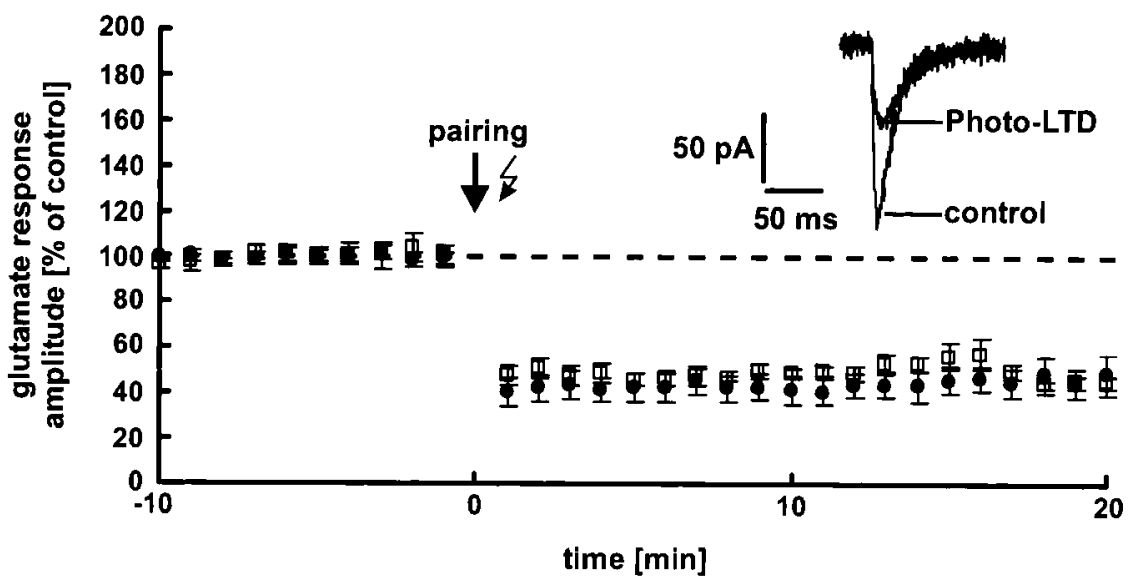

tamate stimulates a bigger membrane area of $\sim 10 \mu \mathrm{m}$ diameter, thereby also activating extrasynaptic receptors, which lie adjacent to the postsynaptic densities (Craig et al., 1994; Baude et al., 1995). Thus, the following scenario seems to be conceivable: Synaptic LTP causes incorporation of new AMPA receptors (or their phosphorylation) specifically at the synaptic sites. These new (or newly phosphorylated) receptors are not detected by glutamate uncaging because the number is very small relative to the many extrasynaptic receptors that give rise to the uncaging response. We cannot rule out this hypothesis completely. Nevertheless, it seems to be very unlikely because of several observations. (1) The density of glutamate receptors at synaptic sites is significantly greater compared with extrasynaptic sites (Jones and Baughman, 1991; Craig et al., 1994; Kornau et al., 1995; Rao and Craig, 1997; O’Brien et al., 1998). (2) Fast application of glutamate to dendritic outside-out patches from hippocampal CA1 pyramidal neurons evokes currents that are primarily mediated by synaptic glutamate receptors (Andrásfalvy and Magee, 2001). (3) In our experiments, glutamate was applied to the layer 4 region of the apical dendrite. In this region, the apical dendrite shows the highest density of spines (Kunz et al., 1972) and thus the highest density of synaptic glutamate receptors.

Several studies provided evidence for a contribution of AMPA receptor redistribution to the expression of LTP (for review, see Lüscher et al., 2000). Thus, lateral movement of AMPA receptors from extrasynaptic sites to the postsynaptic density could theoretically explain why the postsynaptic glutamate sensitivity remained unchanged after LTP induction. Nevertheless, direct evidence for a lateral movement of AMPA receptors during LTP has not been provided up to now. Moreover, recycling of AMPA receptors seems to be responsible for AMPA receptor redistribution during LTP (Lüscher et al., 2000). This phenomenon should have been detected in our glutamate uncaging experiments.

What could be the mechanism of presynaptic LTP? Most of the available evidence speaks in favor of a postsynaptic $\mathrm{Ca}^{2+}$ dependent induction mechanism of neocortical LTP (Malenka, 1995). Thus, a presynaptic expression of LTP would require a retrograde signal between the postsynaptic and presynaptic sites. Candidate molecules fulfilling the criteria of a retrograde messenger are arachidonic acid, nitric oxide (NO), and carbon monoxide. An involvement of NO in the generation of LTP has been shown for the hippocampus (Zhuo et al., 1993; O’Dell et al., 1994;
Arancio et al., 1996) as well as the neocortex (Haul et al., 1999; Volgushev et al., 2000). Mediated by a retrograde messenger, presynaptic LTP should result from an enhanced release of neurotransmitter. This has been shown directly by Malgaroli et al. (1995), who reported enhanced synaptic vesicle cycling during hippocampal LTP, and recently by Zakharenko et al. (2001). Such an effect can be caused by an increased release probability, which has been described for neocortical synapses (Volgushev et al., 1997). Alternatively, an enhancement of presynaptic neuronal excitability by correlated presynaptic and postsynaptic activity (Ganguly et al., 2000) is also conceivable.

Complementing our results, hippocampal mossy fibers generate presynaptic, protein kinase A-dependent LTP (Huang et al., 1994; Weisskopf et al., 1994). Similar presynaptic forms of LTP have also been described for cerebellar parallel fibers (Salin et al., 1996) and corticothalamic synapses (Castro-Alamancos and Calcagnotto, 1999). It has been suggested that these forms of LTP are induced by a rise in the presynaptic $\mathrm{Ca}^{2+}$ concentration. However, most of the available evidence speaks in favor of a postsynaptic induction of neocortical LTP. Thus, we propose a postsynaptic induction and presynaptic expression mechanism of neocortical LTP. This kind of LTP has also been described for the lateral amygdala (Huang and Kandel, 1998).

Regarding LTD, the decrease in glutamate sensitivity during synaptic LTD develops more slowly than synaptic LTD itself. This may indicate a slow spread of synaptic LTD to adjacent synapses and/or extrasynaptic receptors, which are also activated by glutamate uncaging. A spread of LTD, as well as of LTP, over an area larger than the region of induction has been described previously (Engert and Bonhoeffer, 1997; Wang et al., 2000). An alternative explanation for the different time course could be a presynaptic contribution to the early phase of synaptic LTD. However, because of the equal amount of amplitude reduction during photo-LTD and synaptic LTD, this possibility seems to be unlikely.

Photo-LTD and synaptic LTD are expressed very quickly. The reduction in the amplitude of the glutamate response, as well as of the EPSP, was always apparent $1 \mathrm{~min}$ after the $5 \mathrm{~Hz}$ stimulation. Thus, it should be mediated by a local process, in the direct vicinity of the neuronal membrane. Several studies have shown that rapid modifications of postsynaptic AMPA receptors contribute to the expression of LTP and LTD. For example, LTP in 
the hippocampal CA1 region is accompanied by an increased single-channel conductance of AMPA receptors, which is probably caused by phosphorylation (Benke et al., 1998). This observation is in accordance with two studies showing an increase or decrease in the phosphorylation of specific AMPA receptor subunits during LTP and LTD, respectively (Barria et al., 1997; Lee et al., 2000). Thus, it seems likely that neocortical LTD is expressed by a similar mechanism. This is also indicated by the involvement of protein phosphatases in the expression of hippocampal photo-LTD (Kandler et al., 1998). Another possible mechanism of neocortical LTD could be a decrease in the number of synaptic glutamate receptors. Such phenomena, mediated by a rapid redistribution of synaptic glutamate receptors, have been shown by Carroll et al. (1999).

The notion that NMDA receptor-dependent LTP and LTD have different expression mechanisms brings up the issue of the reversibility of these forms of synaptic plasticity. Common mechanisms of expression make LTP/LTD very attractive for a bidirectional and reversible adjustment of synaptic strength. However, if LTP and LTD were expressed differentially, they would not reverse each other. We cannot address this issue conclusively. However, from a theoretical point of view, it is conceivable that the same synapse can express LTP and LTD postsynaptically as well as presynaptically. Under these conditions, LTP and LTD, sharing a common mechanism of expression, could reverse each other. This hypothesis is strengthened by several studies that provided evidence for NMDA receptor-dependent and postsynaptically expressed as well as metabotropic glutamate receptordependent and presynaptically expressed LTD in the hippocampus and the amygdala (Kandler et al., 1998; Wang and Gean, 1999; Lin et al., 2000; Watabe et al., 2002).

In summary, the present study provides strong evidence for a postsynaptic expression of neocortical LTD and favors a primarily presynaptic locus of neocortical LTP. Whether this finding only holds true for synapses on neocortical layer 5 pyramidal neurons or whether it is a more general principle will have to be examined in future studies.

\section{REFERENCES}

Andrásfalvy BK, Magee JC (2001) Distance-dependent increase in AMPA receptor number in the dendrites of adult hippocampal CA1 pyramidal neurons. J Neurosci 21:9151-9159.

Andreasen M, Hablitz JJ (1994) Paired-pulse facilitation in the dentate gyrus: a patch-clamp study in rat hippocampus in vitro. J Neurophysiol $72: 326-336$.

Arancio O, Kandel ER, Hawkins RD (1995) Activity-dependent longterm enhancement of transmitter release by presynaptic $3^{\prime}, 5^{\prime}$-cyclic GMP in cultured hippocampal neurons. Nature 376:74-80.

Arancio O, Kiebler M, Lee CJ, Lev-Ram V, Tsien RY, Kandel ER, Hawkins RD (1996) Nitric oxide acts directly in the presynaptic neuron to produce long-term potentiation in cultured hippocampal neurons. Cell 87:1025-1035.

Barria A, Muller D, Derkach V, Griffith LC, Soderling TR (1997) Regulatory phosphorylation of AMPA-type glutamate receptors by CaM-KII during long-term potentiation. Science 276:2042-2045.

Baude A, Nusser Z, Molnar E, McIlhinney RA, Somogyi P (1995) High-resolution immunogold localization of AMPA type glutamate receptor subunits at synaptic and non-synaptic sites in rat hippocampus. Neuroscience 69:1031-1055.

Bear MF (1995) Mechanism for a sliding synaptic modification threshold. Neuron 15:1-4.

Benke TA, Luthi A, Isaac JT, Collingridge GL (1998) Modulation of AMPA receptor unitary conductance by synaptic activity. Nature 393:793-797.

Bliss TV, Collingridge GL (1993) A synaptic model of memory: longterm potentiation in the hippocampus. Nature 361:31-39.

Bolshakov VY, Siegelbaum SA (1995) Regulation of hippocampal transmitter release during development and long-term potentiation. Science 269:1730-1734.

Carroll RC, Lissin DV, von Zastrow M, Nicoll RA, Malenka RC (1999)
Rapid redistribution of glutamate receptors contributes to long-term depression in hippocampal cultures. Nat Neurosci 2:454-460.

Castro-Alamancos MA, Calcagnotto ME (1999) Presynaptic long-term potentiation in corticothalamic synapses. J Neurosci 19:9090-9097.

Craig AM, Blackstone CD, Huganir RL, Banker G (1994) Selective clustering of glutamate and gamma-aminobutyric acid receptors opposite terminals releasing the corresponding neurotransmitters. Proc Natl Acad Sci USA 91:12373-12377.

Davies SN, Lester RA, Reymann KG, Collingridge GL (1989) Temporally distinct pre- and post-synaptic mechanisms maintain long-term potentiation. Nature 338:500-503.

Dodt HU, Frick A, Kampe K, Zieglgänsberger W (1998) NMDA and AMPA receptors on neocortical neurons are differentially distributed. Eur J Neurosci 10:3351-3357.

Dodt HU, Eder M, Frick A, Zieglgänsberger W (1999) Precisely localized LTD in the neocortex revealed by infrared-guided laser stimulation. Science 286:110-113.

Eder M, Rammes G, Zieglgänsberger W, Dodt HU (2001) GABA and $\mathrm{GABA}_{\mathrm{B}}$ receptors on neocortical neurons are differentially distributed. Eur J Neurosci 13:1065-1069.

Engert F, Bonhoeffer T (1997) Synapse specificity of long-term potentiation breaks down at short distances. Nature 388:279-284.

Engert F, Bonhoeffer T (1999) Dendritic spine changes associated with hippocampal long-term synaptic plasticity. Nature 399:66-70.

Feldman DE, Nicoll RA, Malenka RC, Isaac JT (1998) Long-term depression at thalamocortical synapses in developing rat somatosensory cortex. Neuron 21:347-357.

Ganguly K, Kiss L, Poo M (2000) Enhancement of presynaptic neuronal excitability by correlated presynaptic and postsynaptic spiking. Nat Neurosci 3:1018-1026.

Goda Y, Stevens CF (1996) Long-term depression properties in a simple system. Neuron 16:103-111.

Hansel C, Artola A, Singer W (1997) Relation between dendritic Ca ${ }^{2+}$ levels and the polarity of synaptic long-term modifications in rat visual cortex neurons. Eur J Neurosci 9:2309-2322.

Haul S, Godecke A, Schrader J, Haas HL, Luhmann HJ (1999) Impairment of neocortical long-term potentiation in mice deficient of endothelial nitric oxide synthase. J Neurophysiol 81:494-497.

Hayashi Y, Shi SH, Esteban JA, Piccini A, Poncer JC, Malinow R (2000) Driving AMPA receptors into synapses by LTP and CaM KII: requirement for GluR1 and PDZ domain interaction. Science 287:2262-2267.

Huang YY, Kandel ER (1998) Postsynaptic induction and PKA-dependent expression of LTP in the lateral amygdala. Neuron 21:169-178.

Huang YY, Li XC, Kandel ER (1994) cAMP contributes to mossy fiber LTP by initiating both a covalently mediated early phase and macromolecular synthesis-dependent late phase. Cell 79:69-79.

Isaac JT, Hjelmstad GO, Nicoll RA, Malenka RC (1996) Long-term potentiation at single fiber inputs to hippocampal CA1 pyramidal cells. Proc Natl Acad Sci USA 93:8710-8715.

Jones KA, Baughman RW (1991) Both NMDA and non-NMDA subtypes of glutamate receptors are concentrated at synapses on cerebral cortical neurons in culture. Neuron 7:593-603.

Kandler K, Katz LC, Kauer JA (1998) Focal photolysis of caged glutamate produces long-term depression of hippocampal glutamate receptors. Nat Neurosci 1:119-123.

Kornau HC, Schenker LT, Kennedy MB, Seeburg PH (1995) Domain interaction between NMDA receptor subunits and the postsynaptic density protein PSD-95. Science 269:1737-1740.

Kullmann DM, Nicoll RA (1992) Long-term potentiation is associated with increases in quantal content and quantal amplitude. Nature 357:240-244.

Kullmann DM, Siegelbaum SA (1995) The site of expression of NMDA receptor-dependent LTP: new fuel for an old fire. Neuron 15:997-1002.

Kunz G, Kirsche W, Wenzel J, Winkelmann E, Neumann H (1972) Quantitative studies on the dendrite spines of pyramidal neurons in the rat sensory cortex. Z Mikrosk Anat Forsch 85:397-416.

Lee HK, Barbarosie M, Kameyama K, Bear MF, Huganir RL (2000) Regulation of distinct AMPA receptor phosphorylation sites during bidirectional synaptic plasticity. Nature 405:955-959.

Liao D, Hessler NA, Malinow R (1995) Activation of postsynaptically silent synapses during pairing-induced LTP in CA1 region of hippocampal slice. Nature 375:400-404.

Lin HC, Wang SJ, Luo MZ, Gean PW (2000) Activation of group II metabotropic glutamate receptors induces long-term depression of synaptic transmission in the rat amygdala. J Neurosci 20:9017-9024.

Lledo PM, Zhang X, Sudhof TC, Malenka RC, Nicoll RA (1998) Postsynaptic membrane fusion and long-term potentiation. Science 279:399-403

Lüscher C, Xia H, Beattie EC, Carroll RC, von Zastrow M, Malenka RC, Nicoll RA (1999) Role of AMPA receptor cycling in synaptic transmission and plasticity. Neuron 24:649-658.

Lüscher C, Nicoll RA, Malenka RC, Muller D (2000) Synaptic plasticity and dynamic modulation of the postsynaptic membrane. Nat Neurosci 3:545-550.

Malenka RC (1995) Synaptic plasticity in hippocampus and neocortex: a 
comparison. In: The cortical neuron (Gutnick MJ, Mody I, eds), pp 98-108. New York: Oxford UP.

Malgaroli A, Tsien RW (1992) Glutamate-induced long-term potentiation of the frequency of miniature synaptic currents in cultured hippocampal neurons. Nature 357:134-139.

Malgaroli A, Ting AE, Wendland B, Bergamaschi A, Villa A, Tsien RW, Scheller RH (1995) Presynaptic component of long-term potentiation visualized at individual hippocampal synapses. Science 268:1624-1628.

Malinow R, Tsien RW (1990) Presynaptic enhancement shown by whole-cell recordings of long-term potentiation in hippocampal slices. Nature 346:177-180.

Malinow R, Mainen ZF, Hayashi Y (2000) LTP mechanisms: from silence to four-lane traffic. Curr Opin Neurobiol 10:352-357.

Manabe T, Renner P, Nicoll RA (1992) Postsynaptic contribution to long-term potentiation revealed by the analysis of miniature synaptic currents. Nature 355:50-55.

Matsuzaki M, Ellis-Davies GC, Nemoto T, Miyashita Y, Iino M, Kasai H (2001) Dendritic spine geometry is critical for AMPA receptor expression in hippocampal CA1 pyramidal neurons. Nat Neurosci 4:1086-1092.

Nayak A, Zastrow DJ, Lickteig R, Zahniser NR, Browning MD (1998) Maintenance of late-phase LTP is accompanied by PKA-dependent increase in AMPA receptor synthesis. Nature 394:680-683.

O'Brien RJ, Lau LF, Huganir RL (1998) Molecular mechanisms of glutamate receptor clustering at excitatory synapses. Curr Opin Neurobiol 8:364-369.

O'Dell TJ, Huang PL, Dawson TM, Dinerman JL, Snyder SH, Kandel ER, Fishman MC (1994) Endothelial NOS and the blockade of LTP by NOS inhibitors in mice lacking neuronal NOS. Science 265:542-546.

Oliet SH, Malenka RC, Nicoll RA (1996) Bidirectional control of quantal size by synaptic activity in the hippocampus. Science 271:1294-1297.

Peters A (1987) Number of neurons and synapses in primary visual cortex. In: Cerebral cortex: further aspects of cortical function, including hippocampus (Peters A, Jones EG, eds), pp 267-294. New York: Plenum.

Rao A, Craig AM (1997) Activity regulates the synaptic localization of the NMDA receptor in hippocampal neurons. Neuron 19:801-812.

Salin PA, Scanziani M, Malenka RC, Nicoll RA (1996) Distinct shortterm plasticity at two excitatory synapses in the hippocampus. Proc Natl Acad Sci USA 93:13304-13309.

Shi SH, Hayashi Y, Petralia RS, Zaman SH, Wenthold RJ, Svoboda K, Malinow R (1999) Rapid spine delivery and redistribution of AMPA receptors after synaptic NMDA receptor activation. Science 284:1811-1816.

Staubli U, Lynch G (1990) Stable depression of potentiated synaptic responses in the hippocampus with 1-5 Hz stimulation. Brain Res 513: 113-118.

Stevens CF, Wang Y (1994) Changes in reliability of synaptic function as a mechanism for plasticity. Nature 371:704-707.

Stuart GJ, Dodt HU, Sakmann B (1993) Patch-clamp recordings from the soma and dendrites of neurons in brain slices using infrared video microscopy. Pflügers Arch 423:511-518.

Trommald M, Hulleberg G, Andersen P (1996) Long-term potentiation is associated with new excitatory spine synapses on rat dentate granule cells. Learn Mem 3:218-228.

Tsumoto T (1992) Long-term potentiation and long-term depression in the neocortex. Prog Neurobiol 39:209-228.

Volgushev M, Voronin LL, Chistiakova M, Singer W (1997) Relations between long-term synaptic modifications and paired-pulse interactions in the rat neocortex. Eur J Neurosci 9:1656-1665.

Volgushev M, Balaban P, Chistiakova M, Eysel UT (2000) Retrograde signalling with nitric oxide at neocortical synapses. Eur J Neurosci 12:4255-4267.

Wang SJ, Gean PW (1999) Long-term depression of excitatory synaptic transmission in the rat amygdala. J Neurosci 19:10656-10663.

Wang SS, Khiroug L, Augustine GJ (2000) Quantification of spread of cerebellar long-term depression with chemical two-photon uncaging of glutamate. Proc Natl Acad Sci USA 97:8635-8640.

Watabe AM, Carlisle HJ, O'Dell TJ (2002) Postsynaptic induction and presynaptic expression of group 1 mGluR-dependent LTD in the hippocampal CA1 region. J Neurophysiol 87:1395-1403.

Weeks AC, Ivanco TL, Leboutillier JC, Racine RJ, Petit TL (1999) Sequential changes in the synaptic structural profile following longterm potentiation in the rat dentate gyrus: I. The intermediate maintenance phase. Synapse 31:97-107.

Weisskopf MG, Castillo PE, Zalutsky RA, Nicoll RA (1994) Mediation of hippocampal mossy fiber long-term potentiation by cyclic AMP. Science 265:1878-1882

Zakharenko SS, Zablow L, Siegelbaum SA (2001) Visualization of changes in presynaptic function during long-term synaptic plasticity. Nat Neurosci 4:711-717.

Zhuo M, Small SA, Kandel ER, Hawkins RD (1993) Nitric oxide and carbon monoxide produce activity-dependent long-term synaptic enhancement in hippocampus. Science 260:1946-1950. 